\title{
Olhar testemunhal e representação da ação na fotografia
}

\author{
Benjamim Picado 1 \\ Universidade Federal da Bahia \\ benjamin@ufba.br
}

\begin{abstract}
Resumo: propomos, neste texto, uma análise dos aspectos codificados do gesto humano capturado na fotografia: tomando especificamente o caso do embargo visual das ações no fotojornalismo contemporâneo, examinaremos o modo como os princípios da representação pictórica de situações narrativas estrutura o discurso visual da fotografia de ações. Tomando partido das idéias de Gombrich sobre os princípios da representação pictórica das atitudes humanas, identificamos o gesto humano capturado na fotografia como estando cindido entre dois aspectos principais de sua codificação: no plano de sua ritualização (a normalização dos gestos tendo por modelo suas funções retóricas), ou por referência aos aspectos expressionais da representação do gesto humano (ou seja, pela geração de um pathos, modelado no nível da iconicidade da imagem) isto é, pela produção de uma simaptia sensorial da imagem com aspectos da experiência das personagens da cena.
\end{abstract}

Résumé: dans ce texte, nous proposons une analyse des aspects de codage du geste, dans ses relations avec l'arrêt des actions de la part de la photographie : en partant du cas de l'arrêt de l'action dans le photojournalisme contemporain, nous examinons les manières dans lesquelles les principes picturaux de la représentation peuvent servir comme une structure du discours visuel dans la photographie. En partant aussi des idées de Gombrich sur les principes de la représentation picturale des actions humaines, nous identifions l'arrêt du geste dans la photographie comme étant divisé entre deux traits principaux de son codage : d'une coté, nous identifions cette normalisation du geste avec les procès de ritualisation de l'attitude humaine ; d'autre part, le geste est identifié avec les aspects plus expressives de la représentation (donc avec la génération d'un pathos, que se trouve traduit dans sa forme iconique), i.e., pour la production d'une sympathie sensorielle de l'image avec les aspects de l'expérience des personnages de la scène capturé..

\begin{abstract}
: in this text, we propose an analysis of the coded aspects of human gesture, in the ways we find it captured in photography: taking advantage of the case of visual arresting of action in contemporary photojournalism, we examine the ways by which the pictorial principles of representation might serve as a structure of the visual discourse in photography. Taking a stand with Gombrich's
\end{abstract}

${ }^{1} \mathrm{PhD}$. Universidade Federal da Bahia. 
ideas on the principles of pictorial representation of human action, we identify the arrested gesture in photography as divided between two main aspects of its codification: on one hand, we identify this normalization of gesture with the processes of ritualization of human attitude; on the other hand, the gesture is identified with the expressional traits of representation (thus with the generation of some pathos, which is found translated in a iconic fashion), i.e., by the production of a sensorial sympathy of the image with aspects of the experience of the characters of the scene captured.

Resumen: en este texto, proponemos un analisis de los aspectos de codificación del gesto, em sus relaciones com el arresto de las acciones por parte de la fotografia: empezando por el caso de la captura de l'acción al fotoperiodismo contemporaneo, buscamos examinar las formas en las quales los principios pictuarels de la representacion pueden servir como estructuración del discurso visual de la fotografia. Partindo también de las ideas de Gombrich sobre los principios de la representación pictural de las acciones humanas, nosostros identificamos el arresto del gesto em la fotografia como estando divisado entre dos aspectos pricipales de su codificación: de uma parte, identificamos esta normalización com el procés de ritualización del atitud gestual; de otra parte, el gesto és identificado com los aspectos de la expressión, inherente à la representación (asi siendo, com la géneración de um pathos, traducido à la forma de um icone), ou por la produción de uma simaptia senorial de l'imagen com los aspectos de la experiencia de las personages de la escena capturada.

Palavras-chave: representação, fotografia, ação.

Mots-clé: représentation, photographie, action.

Key-words: representation, photography, action.

Palabras clave: representacion, fotografia, acción.

\section{Testemunho e indexicalidade: instantaneidade e efeito de discurso na fotografia}

Propomos aqui um exercício de análise imanente da imagem fotográfica, de modo a que possamos reconhecer em alguns de seus elementos, ditos internos, certos operadores deste fenômeno muito próprio à história das representações visuais, que seria o de um efeito de discurso, especialmente associado à compreensão das imagens figurativas: de todo modo, o problema das relações entre o discurso narrativo e as artes visuais não constitui uma novidade, ao menos para o campo da história das artes 
visuais. Entretanto, ele ainda suscita alguma perplexidade, especialmente quando nos tornamos ao campo do estudo sobre processos e fenômenos da comunicação mediática.

Nossa proposição tem, assim, o objetivo de incorporar algo desta transparência com a qual as teorias e métodos da história da arte operam estes elementos da visualidade, na representação, como propriedades de uma intenção comunicacional: não propomos, entretanto, a incorporação destes operadores metodológicos com o mesmo tipo de finalidade que caracteriza seu emprego nas teorias da arte, em geral. Em termos, a idéia de que estes elementos de modelação icônica do discurso visual sejam operadores de uma possível hermenêutica visual, não devem ser apropriados na perspectiva exclusiva de auxílio a um firmamento analítico sobre a origem e o desenvolvimento das escolas estilísticas específicas (como é certamente o caso de muitos dos teóricos que trabalham com estas questões nos quadros da história da arte) $)^{2}$.

Em Gombrich, por outro lado, encontraremos fartas sugestões de como o problema da representação pictórica pode interessar à comunicação: sabemos que a expressão, própria a certas pinturas, é o resultado de certas operações internas ao discurso visual, e que podem ser objeto de uma interrogação da parte do estudioso dos processos e fenômenos comunicacionais. Isto posto, vale dizer que a compreensão dos modos pelos quais uma propriedade dos objetos da percepção, como a do movimento, é rendida visualmente na pintura (na forma de uma imagem fixa), não nos

\footnotetext{
2 Assim sendo, categorias como "linear" e "pictórico", que estão na raiz do modelo de crítica historiográfica (próprias à escola crítica de um Wölfflin, por exemplo), não têm aqui o propósito de auxiliar na determinação das diferenças entre os estilos figurativos do Clássico e do Barroco: muito antes disto, propõem-se apenas a sustentar, de um ponto de vista analítico, uma melhor segmentação dos modos discursivos próprios à realização do efeito plástico da representação de ações, com finalidade dramática (entendido aqui o pressuposto de que uma tal caracterização do problema seja de algum concernimento ao campo da comunicação visual). Cf. Wölfflin, Heirich. "O Linear e o pictórico". In: Conceitos Fundamentais da História da Arte (trad. João Azenha Jr.). São Paulo: Martins Fontes (1996): pp. 25,98.
} 
instrui apenas sobre os operadores do discurso expressional na arte, mas podem muito bem ser apropriadas à compreensão de como, por outro lado, percebemos fotografias de ação, tão comuns ao gênero do fotojornalismo. Assim sendo, Gombrich sugere que o estudo dos recursos pictóricos da expressão constituem-se como um campo de provas privililegiado para a pesquisa sobre modalidades não-verbais de comunicação.

Tomando-se partido destas sugestões, podemos começar a explorar a questão de um hipotético modelo de discursividade visual, oriunda da compreensão sobre os mecanismos da representação pictórica: podemos reconhecer aí os meios e modalidades próprias à construção de um efeito de discurso na fotografia, especialmente quando identificamos a representação da ação como um de seus motivos principais.

A rendição fotográfica da sensação de movimento requer que a representação dos elementos capturados no campo visual seja capaz de nos restituir, através dos procedimentos próprios à sua exibição, a uma espécie de domínio partilhado das figurações e das percepções: nos encontramos aqui no limite daquilo que Gombrich designa como sendo o "princípio do olhar testemunhal”, próprio sobretudo à origem das narrações visuais na fase áurea da Antiguidade grega; os operadores deste fenômeno, pelo qual a matéria da representação ascende à condição de um testemunho vicário, não poderão ser identificados senão por uma consideração dos valores comunicacionais e expressionais que atribuímos aos gestos, à postura corporal, e à aparência e expressão fisionômicas³.

Freqüentemente, em nossa experiência cotidiana com a fotografia (e, normalmente, em auxílio a regimes discursivos variáveis, desde a

3 Cf. Gombrich, E.H. "Action and expression in western art". In: The Image and the Eye: further studies in the psychology of pictorial representation. London: Phaidon (1982): pp. 78,104 . 
representação de indivíduos, passando pela narração de reportagem sobre acontecimentos, até o discurso persuasório da publicidade e do investimento erótico de produtos ou corpos), atribuímos a certas características materiais das imagens (suas propriedades sensíveis, sua modalização em aspectos como a cor, o contraste, a intensidade) uma co-naturalidade com respeito ao funcionamento discursivo de nossas práticas enunciativas; intuímos, portanto, que os aspectos plásticos da imagem portam uma espécie de valor semântico ou proposicional.

Uma vez, entretanto, que partindo desta intuição, nos detenhamos mais fortemente sobre uma exploração deste fenômeno (sobre cujo domínio os primeiros teóricos designavam como “comunicação não-verbal”), enfrentamos certas dificuldades em especificar o papel destes operadores de modelação propriamente icônica na construção deste efeito discursivo, próprio á experiência das imagens: assim sendo, parece constituir uma interdição própria à ordem mesma dos fenômenos visuais que a definição do funcionamento das imagens, com fins comunicacionais, nos impeça de acessar sua estruturação a partir de um olhar que privilegie esta sua dimensão plástica de manifestação.

As primeiras investidas semiológicas sobre a significação da fotografia não pareceriam, nesta perspectiva, incorretas, do ponto de vista analítico ou metodológico pois, ao falarmos em significação visual, sem fazer concorrer para a matéria icônica do discurso a ordem configuradora do lingüístico, separaríamos no fenômeno um aspecto que tornaria a experiência da imagem, a rigor, infensa a qualquer compreensão, em termos discursivos.

A grande linhagem histórica dos debates semióticos acerca do estatuto comunicacional da imagem definir-se-ia, portanto, como um esforço por individuar, do ponto de vista de uma análise rentável dos materiais visuais, as chaves metodológicas mais adequadas para fazer entender os procedimentos 
pelos quais certos materiais desprovidos daqueles aspectos que definiriam a unidade do sentido, numa ordem lingüística da compreensão, ainda assim poderiam vigorar em nossa experiência como instâncias de uma forma discursiva determinada: já pudemos destacar, em outras oportunidades, a herança que as disciplinas da linguagem e do sentido legaram para o tratamento que as ciências sociais puderam ofertar à análise de fenômenos, como a transmissão do parentesco, a fabricação social das aparências, a troca simbólica, dentre tantos outros.

Neste contexto, o tratamento dos fenômenos e processos comunicacionais, tomados como instâncias de um discurso teoricamente especificável em termos semânticos, não constituiu grande novidade para o solo heurístico da qual se originara esta mesma preocupação: de fato, podemos mesmo dizer que as tópicas próprias a algumas das primeiras investidas semiológicas sobre fenômenos extra-linguísticos tinham por objeto precisamente o universo das comunicações de massa. Poderemos quase que antecipar a ordem temática das significações e da linguagem como um dado tácito destes mesmos discursos, ao considerarmos as manifestações típicas dos estudos sobre fenômenos do campo da comunicação (especialmente quando este faz apelo à idéia de uma "cultura das imagens")4.

No caso da maior parte das vertentes que notabilizaram o discurso das teorias semióticas, podemos flagrar esta pressuposição de que o significado dos ícones deve estar de tal modo instanciado pelas estruturas do discurso enunciativo que poderíamos prescindir, para fins de sua análise, de quaisquer considerações acerca de sua gênese material e plástica nas substâncias propriamente visuais das imagens: já pudemos contestar anteriormente, com alguma ênfase, estas assunções de base sobre a natureza do ordenamento da significação icônica (sobretudo o fato de que elas prescindem do que

4 Cf. Picado, José Benjamim. "Os desafios metodológicos da leitura de imagens: um exame crítico da semiologia visual”. In: Fronteiras. 4:2 (2003): pp. 56, 70. 
poderíamos designar, num linguajar mais próximo ao das teorias poéticas, de uma dimensão propriamente sensorial da programação produtiva de seus efeitos)5.

Por ora, entretanto, nos interessa averiguar esta predominância de um viés semiótico para o tratamento de uma semântica do iconismo, agora numa sede mais analítica do que fortemente teórica: assim sendo, propomos um outro estilo de aproximação à questão, e que nos permita operar, agora numa chave indutiva, a partir de certas classes de problemas que requisitam uma aproximação à imagem, uma vez tomada em seu estatuto de fato discursivo ${ }^{6}$.

O caráter supostamente testemunhal da imagem fotográfica, por exemplo, é uma questão que possui desdobramentos empíricos de tal ordem extensos e diferenciados que poderia constituir uma de nossas classes de problemas7: em diferentes tipos de contexto de apropriação de fotografias,

5 Cf. Picado, José Benjamim. "Do Problema do Iconismo à Ecologia da Representação Pictórica: indicações metodológicas para a análise do discurso visual” . In: Contracampo, 9/2 (2004): pp. 199-220. No que respeita o problema dos modos de programação dos efeitos, tomado em sua dimensão de questão comunicacional, ver: Gomes, Wilson. "Princípios de Poética (com ênfase na poética do cinema” . In, et al.: Comunicação, Representação e Práticas Sociais (Miguel Pereira, Renato Cordeiro Lopes e Vera Follain, orgs.). Rio: PUC-RJ (2004): pp. 93, 126.

${ }^{6}$ De resto, de um ponto de vista puramente teórico, não nos restaria muitas alternativas para o enfrentamento desta dimensão plástica da significação do iconismo (e o conseqüente acolhimento de teorias mais afeitas à problematização estética desta experiência), senão por um radical despedimento da possibilidade mesma de abordá-la, numa perspectiva propriamente semiótica; tantas vezes este ponto tem sido notado por comentadores, que não nos parece ser o caso de aprofundarmos a questão, no nível dos quadros teórico-dedutivos desta disputa. Cf. Valverde, Monclar. "A Instituição do Sentido: a linguagem e a experiência da comunicação". In: Textos de Cultura e Comunicação. 29 (1993): pp. 51,62; vide tb. Parret, Herman. "A Estetização da pragmática". In: A Estética da Comunicação: além da pragmática (trad. Roberta Pires de Oliveira). Campinas: Unicamp (1997): pp. 11,28.

7 No registro propriamente semiológico desta tese, a referência clássica é a do texto de Barthes sobre os limites da conotação da imagem, a propósito da análise da retórica visual publicitária e da fotografia de imprensa, em "La Message photographique" e "La Rhétorique de l'image". Cf. Barthes, Roland. L'Obvie et l'Obtus. Paris: Seuil (1992): pp. 9,42. Entretanto, estamos mais interessados na averiguação de certas resultantes mais contemporâneas deste discurso, muito especialmente quando a questão do valor testemunhal da fotografia se incorpora à discussão sobre sua significação. Interessa-nos especialmente questionar que este valor esteja exclusivamente determinado pelos protocolos discursivos de campos específicos, como o dos enunciados reportativos no jornalismo: esta parece ser uma tese subjacente, por exemplo, às idéias de Eliseo Véron acerca da discursividade das imagens fotográficas. Cf. Véron, Eliseo. 
encontramos esta atribuição de um valor de autenticação, supostamente próprio à imagem fotográfica; exemplos da variedade deste fenômeno encontraremos na utilização destes ícones, com fins de ilustração de narrativas jornalísticas (nas quais a imagem, antes de possuir uma função figurativa, serve apenas para dar conhecimento visual dos elementos de uma reportagem de eventos quaisquer), assim como também na apropriação destas imagens, com fins documentais, em contextos de investigação histórica ou como parte de um sistema de provas, no contexto jurídico ${ }^{8}$.

Em todos estes casos, verificamos que um certo atributo da imagem fotográfica é valorizado como sendo oriundo da própria natureza do dispositivo pelo qual estas imagens são obtidas (com as implicações ontológicas que isto possa acarretar para uma teoria da representação visual): associada a estas visões, podemos identificar uma extensa tradição de discursos, de diferentes origens e cepas teóricas, dedicada a explorar a hipótese de que a imagem fotográfica possui um atributo de imanência com respeito ao campo da referência, de maneira tal que a análise de seus protocolos discursivos pode ser claramente dissociada daquela que caracteriza

“De l'Image Sémiologique aux Discursivités: le temps d'une photo". In: Hermes. 13/14 (1994): pp. 45,64 .

8 As referências a estes aspectos documentais da apropriação da fotografia são bastante extensas, sendo que, para efeito de ilustração, nos detemos apenas sobre alguns dos principais aspectos que articulam a evocação da fotografia no campo das ciências humanas e sociais: a questão do valor testemunhal da foto é certamente o mais evidente destes aspectos, e justifica uma longa linhagem de autores e tradições teóricas dedicadas a ele, desde o campo da historiografia até o das práticas etnográficas. Cf. Collier, John. Antopologia Visual:a fotografia como método de pesquisa. São Paulo: Edusp (1973); Freund, Giselle. Photographie et Societé. Paris: Seuil (1974); Kossoy, Boris. Fotografia e História. São Paulo: Ateliê Cultural (2001); Samain, Ettiene. "Para que a antropologia consiga tornar-se visual". In et al. Brasil, Comunicação, Cultura e Política (Antonio Fausto Neto, José Luiz Braga e Sérgio Dayrell Porto, eds.). Rio: Diadorim (1994): pp. 33,46. Outro aspecto desta valorização do documental na análise da fotografia verifica-se no campo de estudos sobre a apropriação social da foto, especialmente no contexto de práticas corriqueiras, turísticas e familiares, sobre as quais incide o problema da memória e da autenticação fotográfica dos entes e situações. Cf. Batchen, Geoffrey. "Vernacular photographies". In: Each Wild Idea: writing, photograph, history. Cambridge: MIT Press (2002): pp. 56,81; Bourdieu, Pierre (org.). Un Art Moyen: essai sur les usages sociaux de la photographie. Paris: Minuit (1965); Fabris, Annateresa (org.). Fotografia: usos e funções no século XIX. São Paulo: Edusp (1991); Leite, Miriam F.M. Retratos de Família. São Paulo: Edusp (1993). 
o modo de acessar a produção do sentido visual em formas supostamente correlatas, como as da pintura e da escultura9.

Assim sendo, a questão do valor testemunhal e documentário da imagem fotográfica conclamou a discussão sobre o problema da instantaneidade da representação visual, agora numa chave mais própria às discussões sobre os dispositivos técnicos de sua produção: o suposto valor discursivo desta imagem suscitou um fortíssimo discurso, especialmente originário de certas teses semiológicas (mas que tem igualmente, suas contrapartidas numa certa genealogia da imagem fotográfica), e que procura tematizar a possível determinabilidade dos aspectos de registro dos ícones fotográficos na caracterização de seus aspectos representacionais. Estas teses, que sumarizamos sob a rubrica de argumentos do dispositivo, apostam firmemente na idéia de uma indexicalidade originária da significação da fotografia: este valor testemunhal da foto estaria determinado pelo fato de que os aparatos técnicos envolvidos na sua produção nos legariam uma forma de representação que é, também, resultado de processos mecânicos de impregnação do mundo visual em uma superfície sensível.

De algum modo, é este também o problema que demarca aquelas abordagens que partem da idéia de indexicalidade radical, para desenvolver um discurso sobre a significação da fotografia, como no caso das teorias acerca do "ato fotográfico" (ou dos dispositivos pragmáticos para seu reconhecimento sensível e semiósico). Para estas vertentes, a questão da contigüidade factual entre o signo fotográfico e seu referente deve constituir um problema de base para a semiótica da fotografia: de nosso ponto de vista, por outro lado, a significação fotográfica permanece acionando uma estrutura

\footnotetext{
${ }^{9}$ Apenas a título de sugestão, uma breve problematização inicial do caráter puramente documental do testemunho fotográfico (e seus enraizamentos na atividade imaginadora do sujeito apreciador), verifica-se em Manguel, Alberto. "Tina Modotti: a imagem como testemunho". In: Lendo Imagens: uma história de amor e ódio (trad. Rubens Figueiredo, Rosaura Eichemberg e Claudia Strauch). São Paulo: Companhia das Letras (2000): pp. 85,106 .
} 
de compreensão dos signos visuais como sendo aquela que os aloja na condição de signos icônicos ${ }^{10}$.

Não obstante o endereço teórico próprio às teses sobre a exclusividade do dispositivo da representação na fotografia (e suas conseqüências para o argumento acerca da instantaneidade de seu efeito representacional), podemos explorar outras vertentes do discurso teórico sobre a imagem para identificarmos novas encarnações desta mesma idéia de co-naturalidade da fotografia e de seus objetos: podemos avaliar estas questões, à luz de algumas implicações do argumento oferecido por Richard Wollheim, em Art and its Objects, acerca das características próprias à percepção das representações visuais, assim como suas conseqüências para a avaliação do caráter representacional da fotografia ${ }^{11}$.

Nosso propósito agora é o de aprofundar estas conseqüências do discurso sobre as "visões da representação", na medida em que estas impliquem, do mesmo modo que nas teses sobre o dispositivo fotográfico, a idéia da instantaneidade da representação visual na fotografia: já sabemos que o problema da compreensão da fotografia ocorre a Wollheim, no contexto de sua reflexão sobre o tipo de visão característico da interpretação de representações (muito especialmente, dos objetos dotados de qualidades estéticas); neste segmento da experiência empírica, a teoria da realidade não chama seus correlatos em causa pelo aspecto de sua fisicalidade última, mas por um gênero de percepções a que Wollheim designa como visão da representação, concebida como uma contrapartida semântica da experiência estética das obras visuais.

\footnotetext{
10 Para avaliar a história e as posições que caracterizam a tese do dispositivo e a questão da indexicalidade de base do dispositivo fotográfico, vide Dubois, Phillipe. L'Acte

Photographique. Bruxelas: Labour (1983). Na perspectiva mais próxima à iconicidade de base das imagens fotográficas, ver Schaeffer, Jean-Marie. L'Image Précaire: du dispositif photographique. Paris: Seuil (1987).

${ }^{11}$ Cf. Wollheim, Richard. A Arte e seus Objetos (trad. Marcelo Brandão Cipolla). São Paulo: Martins Fontes (1994).
} 
O que parece primeiramente comum a estas percepções é que podemos aplicar a elas determinados padrões de correção visual, cuja origem se encontraria na atividade mesma do artista: a procedência de algo como uma representação dependeria, portanto, de uma determinação originária deste padrão, de tal modo que seu suposto prosseguimento, numa representação particular, definiria a possibilidade de seu acolhimento, no nível da percepção estética; compreender uma obra seria o ato de projetar para suas qualidades materiais as características de um padrão de compreensão.

Decerto que as imagens fotográficas ilustram à perfeição a questão da vigência dos padrões de correção, pois perceber uma fotografia enquanto tal implica que seu apreciador possa localizar-se nas condições próprias à fruição de representações visuais, que são precisamente seus critérios de correção. Isto não obstante, entretanto, outro aspecto essencial da visão da representação parece escapar à fotografia, em razão da natureza mesma de seu dispositivo de produção: segundo Wollheim, a origem destes padrões para a representação pictórica localizar-se-ia na atividade do artista, de tal modo que a visão da representação faz observância, necessariamente, às suas intenções originárias (de modo tal que perceber uma obra, em seu aspecto de representação, é acolhê-la, dentro de padrões, cuja origem última é a intenção artística) $^{12}$.

Ora, no caso da fotografia, não poderíamos supor que a correção visual decorresse exclusivamente desta vontade produtiva originária: e, de fato, Wollheim insiste que a causalidade mecânica do registro fotográfico acarreta que a determinação pela intenção esteja aqui em igualdade de condições, com

\footnotetext{
${ }_{12} \mathrm{O}$ argumento sobre a intenção artística, e seus desdobramentos para o padrão de correção, próprio às visões de representação são desenvolvidos por Wollheim, a propósito da caracterização que ele estabelece para a atividade artística do pintor (e que a diferencia das finalidades outras do ato mesmo de pintar): é no nível artístico desta realização que o problema dos padrões de compreensão próprios á pintura ganham seu estatuto. Cf. Wollheim, Richard. "O Que o artista faz". In: A Pintura como Arte (trad. Vera Pereira). São Paulo: Cossac\&Naify (2002): pp. 13,42.
} 
respeito às características do dispositivo de produção das imagens. Uma resultante possível desta determinação pelo dispositivo verifica-se no plano das diferentes propriedades dos objetos representados, conforme estejamos tratando da experiência própria à pintura ou à fotografia: assim sendo, não podemos, por exemplo, separar na fotografia nossa percepção do modelo da representação de seu objeto correspondente, do mesmo modo como certamente procedemos na pintura (neste último caso, uma imagem mítica não tem como modelo um mito, mas um indivíduo).

É certo que, a determinada altura de seu ensaio, o próprio Wollheim menciona que a fotografia pode ser apropriada para realizar um tipo de efeito próprio às representações pictóricas: posso fotografar um figurante de cinema (ou mesmo um ator), quando representa uma personagem, ou então, uma amiga fantasiada de grã-duquesa; nestes casos específicos, a representação fotográfica realiza um efeito próprio às representações pictóricas, nas quais, como já vimos, há uma dissociação constitutiva entre o modelo e o objeto do signo intencional. De fato, entretanto, na experiência usual das fotografias, estabelece-se uma espécie de vínculo indissolúvel entre a natureza do objeto representado e os materiais ou pessoas que servem a ela de modelos.

Neste ponto, interessa-nos menos avaliar os desdobramentos do discurso de Wollheim (na direção de um aperfeiçoamento da visão própria às representações) ${ }^{13}$, do que identificar este aspecto de aparente comunidade entre suas concepções sobre a representação visual na fotografia e as teses sobre a natureza determinante de seu dispositivo técnico, na constituição de

\footnotetext{
13 De qualquer maneira, a quem quer que possa interessar a discussão destas conseqüências (e que têm enorme importância para a discussão sobre as relações entre representações e modos de ver), sugerimos a leitura dos ensaios nos quais Wollheim retifica suas primeiras concepções acerca dos padrões de correção próprios à visão das representações (enquanto um "ver-como"), na direção de uma nova modalidade de percepção pictórica, a do "ver-em" (com implicações que, inclusive colocarão suas idéias sobre a representação visual em um interessante debate com as teorias de Gombrich). Cf. Wollheim, "Ver-como, ver-em e a representação pictórica”. In: A Arte e seus Objetos, op. cit: pp. 177,194; ver tb. "O que o espectador vê". In: A Pintura como Arte, op. cit: pp. 43,100.
} 
uma experiência própria de suas imagens e produtos: poderíamos nos manter fiéis às idéias de uma visão própria às representações e, ainda assim, preservarmos um discurso sobre a experiência do fotográfico que não se reduzisse a um conhecimento que fosse necessariamente oriundo do dispositivo.

Em termos, devemos nos interrogar se os aspectos causais, ligados à origem da imagem fotográfica, possuem, de fato, um papel determinante na formação de nossas concepções sobre sua relação com padrões de compreensão, como argumenta Wollheim: o fato de não podermos restituir este efeito a um gesto artístico originário e exclusivo não significa que não possamos compreendê-lo a partir de certos aspectos ligados a esta mesma possibilidade (postulando-a, portanto, como originária de um gesto intencional apenas possível ou hipotético).

\section{A apreensão do gesto humano na fotografia: entre o rito simbólico e o pathos icônico}

Se consideramos, por exemplo, o problema com o qual apresentamos este ensaio (a saber, o da atribuição de um efeito de discurso a certas obras do fotojornalismo) ${ }^{14}$, em que sentido poderíamos ainda insistir numa estrita indissociabilidade entre as qualidades próprias à representação e aquelas que são oriundas de seu veículo? Se a requisição de Wollheim atende decerto a uma idéia de representação que é própria à fotografia (e que prima evidentemente por esta suposta imediaticidade entre objeto e modelo), para que supor que, do ponto de vista da percepção, uma fotografia não possa ser acionada a partir de uma demarcação pictórica da interpretação das imagens?

\footnotetext{
14 Já exploramos estas questões, a propósito das relações entre as propriedades visuais da imagem fotográfica e sua apropriação, com fins narrativos mais ou menos específicos, trabalhando especialmente com as imagens de Robert Doisneau. Cf. Schneider, Greice e Picado, José Benjamim. "Construção de Mundos em Fotografias de Representações: supressão e ambigüidade em Robert Doisneau”. In: Significação. 22/1 (2004): pp. 59-78.
} 


\section{compós}

Antes, entretanto, de nos perdermos em divagações excessivamente teóricas, procuremos restituir o quadro desta discussão àquela classe de problemas à qual designamos como caráter testemunhal da fotografia: nossa questão, então, diz respeito aos modos pelos quais as teorias da representação (ao menos no caso da fotografia) implicaram na idéia de um olhar testemunhal o problema da natureza do dispositivo fotográfico. Interroguemo-nos se esta implicação é de algum modo necessária, ou então se não poderíamos acioná-la a partir de outras espécies de enquadramento teórico. Este é fundamentalmente o problema que nos motiva a explorar, em suas resultantes metodológicas, a questão do efeito de discurso, próprio a certas fotografias, e é através dele que propomos uma análise da imagem que se segue (fig.1):

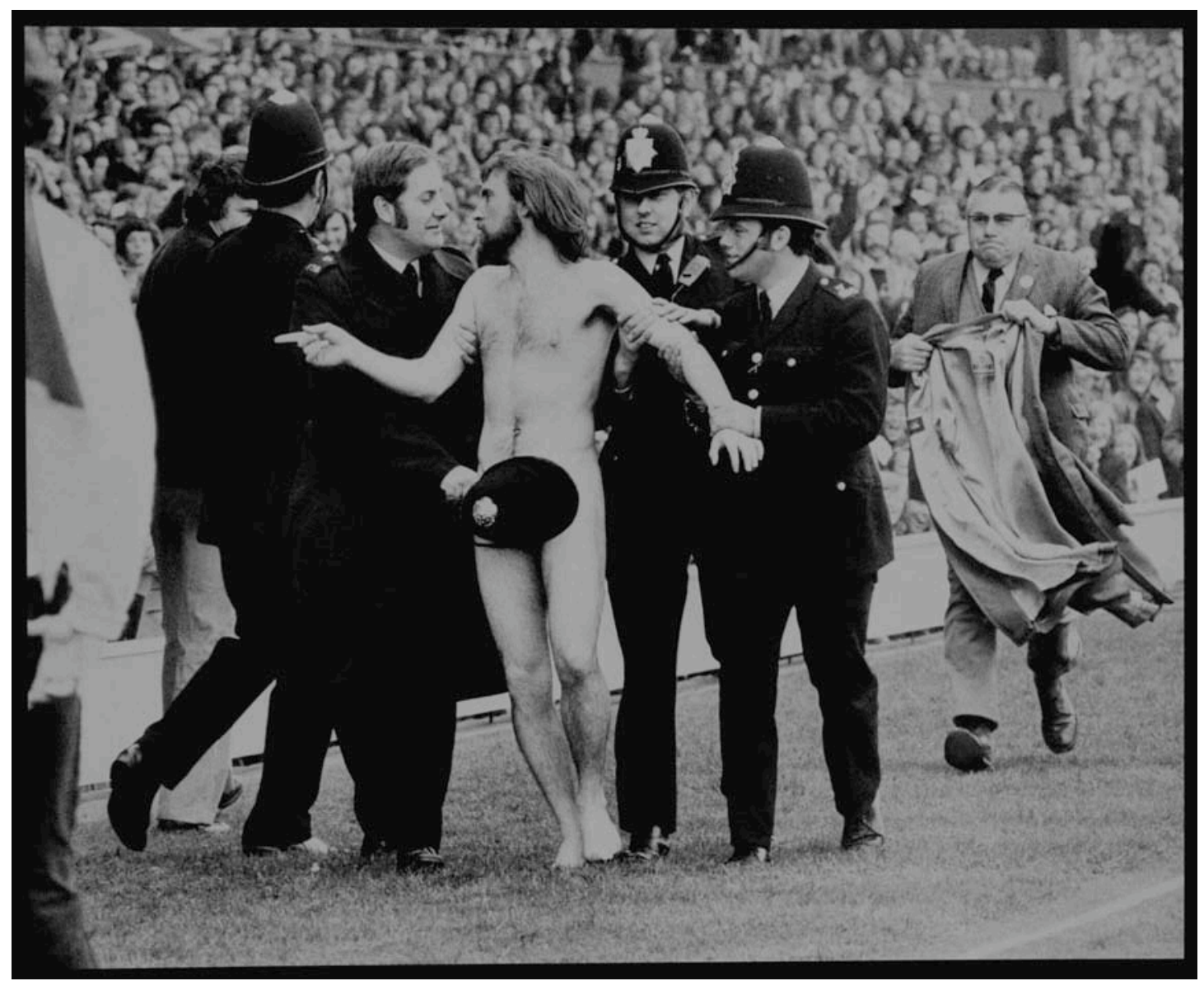

1. Ian Bradshaw, “Twickenham Streaker” (1974) 
Em primeiro lugar, devemos reconhecer que trata-se de um autêntico instantâneo fotográfico, registro de um evento realmente ocorrido e obtido como um recorte (uma espécie de embargo, um arresto visual), no interior de sua integridade espaço-temporal. Não deveríamos supor, neste sentido, que qualquer percepção do mesmo devesse envolver algum aspecto de artificialidade da composição, supostamente própria aos dispositivos pictóricos: qualquer aposta nesta direção significa que não poderíamos ter em conta, no nível de sua avaliação, aqueles aspectos que caracterizam a filogênese desta imagem (sua origem como um puro registro), tomada enquanto um dado de sua eventual significação. Uma análise pictórica da foto a desligaria necessariamente daquelas propriedades supostamente visuais que a vinculam ao dispositivo fotográfico.

Por outro lado, pensando naquilo que, para Wollheim, caracteriza as similaridades da experiência fotográfica com a das imagens pictóricas, esta foto parece também contrariar qualquer tese sobre o poder determinante dos sistemas de correção ligados ao seu dispositivo tecnológico: não nos ocorre pensar nos significados ou na dimensão representacional desta imagem sem aludir aos evidentes aspectos de narratividade, de dramaticidade e, muito especialmente, da organização plástica de elementos que ela é capaz de nos exibir.

Diríamos mais: se é assim, a imagem fotográfica exibe estes aspectos não por envolver algum artifício produtivo (por ter sido feita especialmente para suscitar este efeito), mas justamente por sua origem estar implicada num processo de recorte instantâneo da realidade. Há uma co-extensividade entre as propriedades de ser um instantâneo e ser uma fotografia, nesta imagem: isto se justifica pelo fato de que, na fotografia, estes elementos do arresto temporal foram capturados, numa visão certamente própria ao dispositivo, ao passo que na pintura eles teriam sido construídos artisticamente. 
A discussão sobre a experiência fotográfica poderia dispensar o papel predominante dos dispositivos que entram jogo na experiência estética, mas não poderia se abstrair do fato de que esta experiência é própria a uma modalidade das percepções, a um estilo de visão: estamos, portanto, explorando as qualidades específicas deste tipo de imagem que nos lega a impressão de ter sido subtraída de uma sucessão temporal e extensa das ações; ser um instante é, nestes casos, oferecer-nos a sensação vicária do acontecido apenas no plano de um fragmento eventual do que se passou (e, aparentemente, a fotografia parece exibir-nos uma estrutura mais pregnante deste fenômeno de embargo, inerente às representações visuais do tempo).

Se analisarmos detidamente os elementos desta imagem que configuram seu sentido de ação humana representada, descobriremos, em primeiro lugar, todo um sistema da gestualidade humana encarnado na atitude de suas personagens, e cujo padrão de correção não se encontraria no nível da indexicalidade do registro fotográfico, mas nas chaves propriamente icônicas de sua compreensão. Por outro lado, a legibilidade da presença humana posta na fotografia incorpora certos esquemas de representação que caracterizam a visão e o reconhecimento pictóricos da ação dos personagens no contexto de uma organização dramática dos elementos, de uma cenografia e de uma liturgia próprias, por sua vez, à arte pictórica.

Propomos, então, um percurso detido (e supostamente imanente) pelos elementos deste discurso plástico da fotografia, imaginando poder colher desta análise, um pouco mais à frente, os dados para alguma generalização teórica sobre a estrutura mais profunda desta discursividade visual, própria aos regimes pictóricos: nossa atenção momentânea se detém sobre os aspectos que definem a regularidade do tratamento visual dos gestos, da expressão fisionômica, e, de resto, da representação das ações, como traços pelos quais o sentido discursivo da fotografia se firma como um problema de retórica visual. 
Em primeiro lugar, o movimento e o gesto humanos representados na foto (fig.2): notamos nesta imagem algo a que os historiadores da arte designam como parte de um sistema da gestualística, próprio às representações pictóricas: esta linguagem dos gestos atendeu a fins muito diversificados na história dos estilos, mas, na análise desta fotografia, interessa-nos verificar que a expressão gestual está, de algum modo, remetida precisamente aos marcos da legibilidade. Em primeiro lugar, devemos admitir que as atitudes das personagens desta cena não se abandonam a uma pura gratuidade de sua disposição (não estavam simplesmente dados ao dispositivo), mas se coordenam numa dimensão que não é apenas plástica e expressional, mas também dramática.

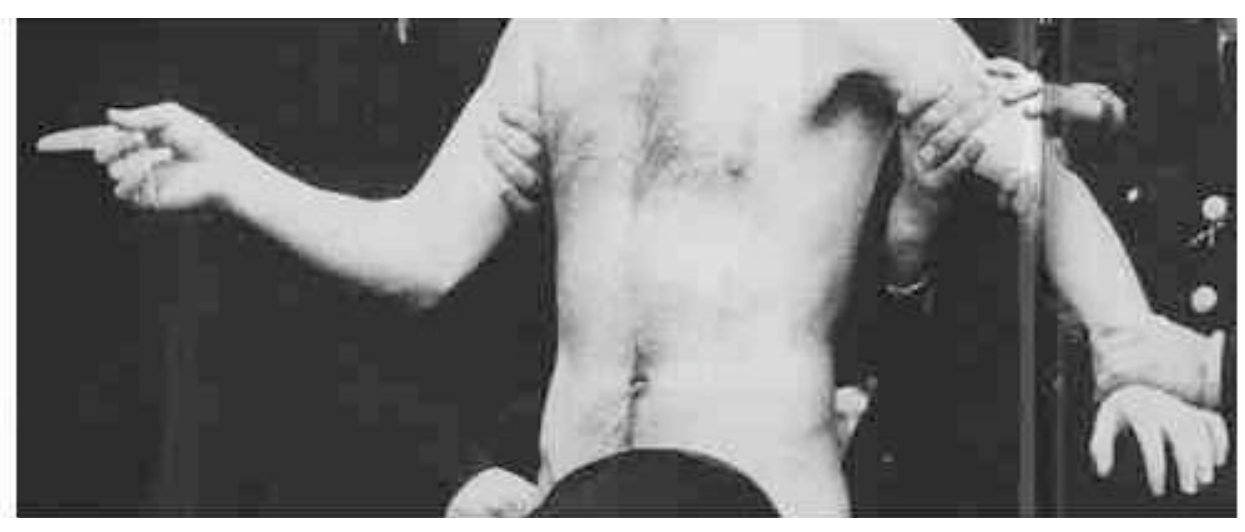

2. "Twickenham Streaker" (detalhe)

Há uma evidente repercussão entre o gesto indicador da personagem principal e a conversação por ele mantida com o policial à esquerda da foto (figs. 3 e 4): não percebemos este fato apenas por ele ter se disposto eventualmente ao olhar do fotógrafo, mas certamente por estarmos habilitados, pelos dados de nossa cultura visual, com esta complementariedade entre o gesto e a disposição para o discurso.

Esta questão do valor discursivo do gesto na representação visual deve ser explorada em dois sentidos principais: em primeiro lugar, há nesta foto 
um evidente aspecto de retorização visual da atitude humana, associado à incorporação discursiva das atitudes corporais das personagens; seus gestos dizem respeito a uma propriedade da representação das ações humanas que se repercute sobre a expressão propriamente verbal das personagens, no campo das ações; o gesto da mão direita do homem nu tem evidente redundância com o ato mesmo da conversação que ele mantém com o policial.
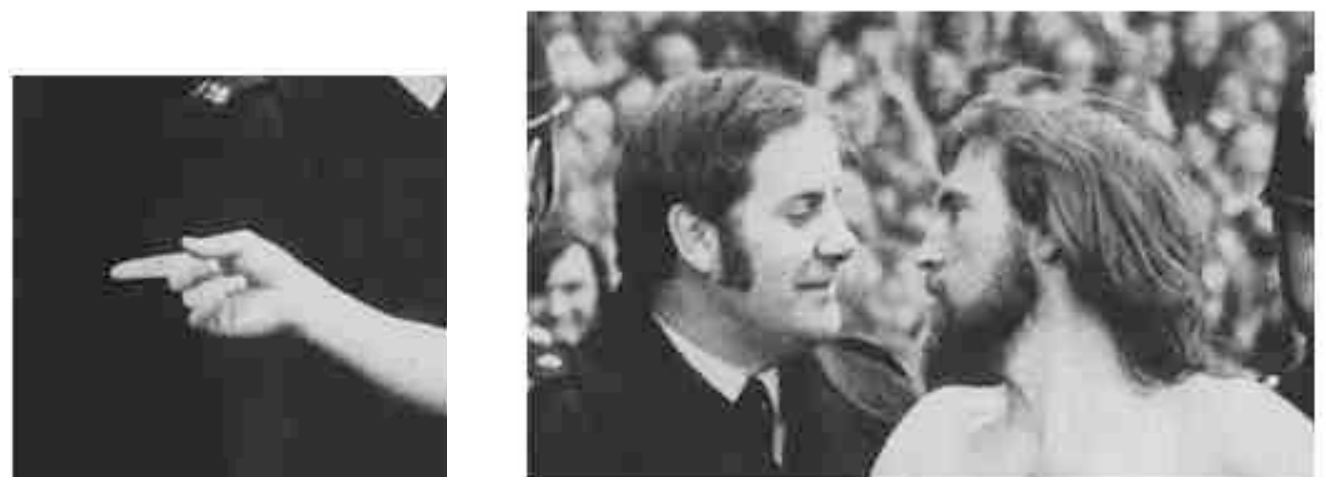

3. e 4. "Twickenham Streaker" (detalhe)

Nossa familiaridade com este fenômeno de repercussões decorre certamente do fato de que nos comportamos usualmente assim, mas o aspecto mais forte da questão diz respeito ao modo como esta experiência é traduzida pictoricamente (e repercutida, em nossos modos de ver a fotografia): estamos habituados a reconhecer em uma certa espécie de tratamento visual dos gestos os correspondentes semióticos de uma conversação, e a história da arte está certamente repleta de exemplos que ilustram precisamente esta suplementariedade que a representação da atitude humana acarreta, em contextos expressivos, especialmente para uma forma de arte à qual faltam precisamente os correlatos verbais.

As formas da realização deste efeito são certamente variáveis: vão desde a pura conceitualidade gestual, na arte cristã do medievo, na qual as atitudes corporais têm a função predominante de fixar o caráter geral das personagens (fig.5), até o alto grau de individuação psicológica das 
disposições e de encarnação física das ações, a partir da Renascença (fig. 6). Isto posto, entretanto, não nos resta dúvidas de que reconhecer nos gestos das personagens desta foto seu devido valor retórico não decorre da pregnância com a qual o registro fotográfico as firmou numa superfície sensível, mas dos hábitos perceptivos com os quais reconhecemos o valor de redundância das atitudes corporais das personagens ${ }^{15}$.

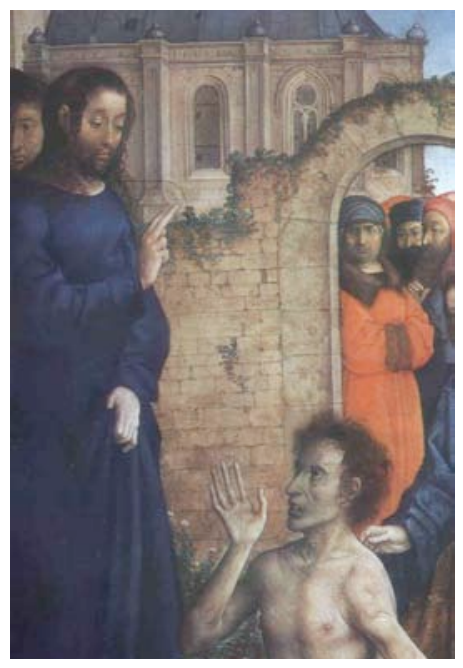

5. Juan de Flandes - "A Ressurreição de Lázaro"c. 1512/1518 (detalhe) - Museu do Prado

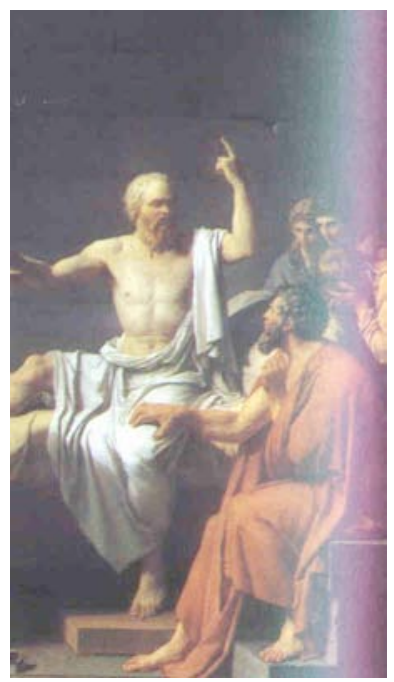

6. Jacques Louis David - “A Morte de Sócrates”,1787 (detalhe) - Metropolitan Museum of Art

${ }_{15}$ Cf. Gombrich, Ernest. "Ritualized gesture and expression in art". In: The Image and the Eye, op.cit.: pp. 64, 77 . 
Há, entretanto, um outro aspecto desta complementariedade entre gestualidade e discurso pictórico que nos interessa aqui, e que terá desdobramentos ao avançarmos nossa análise sobre o caráter testemunhal da fotografia: quando aprofundamos um pouco mais o tipo de relações que as personagens principais entretêm na fotografia, este sentido mais fortemente normatizado da função dos gestos na composição parece ceder lugar a uma certa ambigüidade pela qual atribuímos o desdobramento das ações, aqui capturadas. Nossa atenção recai especialmente sobre o complexo inteiro das relações entre o gesto indicador da personagem principal, os olhares que ele troca com o policial e a mão direita deste que cobre, com seu capacete, a nudez do primeiro (fig. 7 ).

Decerto que a integração do gestual com a relação conversacional ainda é muito evidente na imagem: de fato, é nesta relação entre gesto e fala que se concentra a maior parte das forças que transformam a imagem num sintagma narrativo. $\mathrm{O}$ único elemento externo a este complexo, mas ainda auxiliar ao reforço desta impressão de uma ação em curso, seja talvez a figura à direita e ao fundo e que se aproxima do grupo principal, trazendo um sobretudo para cobrir a nudez da personagem principal (fig 8.).

Mas o caráter dos desfechos concretos para esta ação, e que se anunciam na imagem, não podem ser determinados com grande exatidão, precisamente porque esta interação que as personagens mantêm, no plano dos gestos e dos olhares mútuos, guarda uma certa ambivalência (que parece significar uma cumplicidade, algo prazerosa, entre seus sujeitos), e que jamais se coliga integralmente com o aspecto puramente reportativo e eventual do registro fotográfico (por exemplo, com uma reportagem sobre a prisão de um exibicionista durante a final de um torneio de rugby). 


\section{(e) compós}
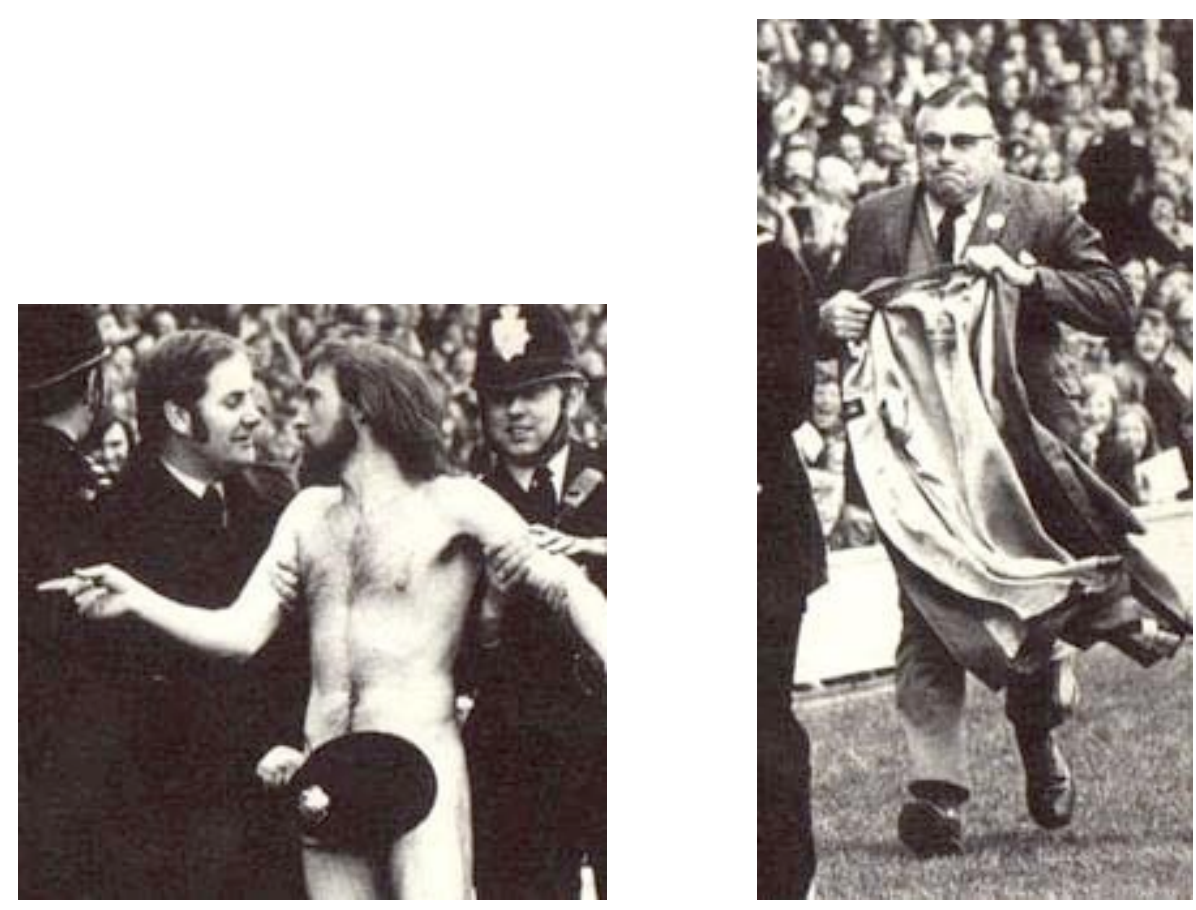

7. e 8. "Twickenham Streaker" (detalhe)

Este fenômeno de repercussões entre a gestualidade e as disposições próprias às personagens da ação não é casual na representação visual (tampouco é o resultado de algum aspecto intrínseco à arte fotográfica ou ainda ao regime de suas relações com o texto escrito, como nos querem fazer supor certas semiologias) ${ }^{16}$, mas se restitui à ordem de um operador visual próprio à arte pictórica. Por exemplo, em seu Trattato della Pintura, Leonardo recomendava ao artista apreender visualmente as figuras com aquela atitude exclusivamente própria à operação na qual serão efetivamente representadas: de modo tal que, ao vê-las, conheçamos imediatamente o que pensam e o que intentam dizer; os meios para a realização deste princípio se dispõem àquele que melhor observar (por exemplo, na linguagem própria aos surdos-mudos)

${ }^{16}$ Cf. Barthes, Roland. "La Réthorique de l'image”. In: L’Obvie et l'Obtus. Paris: Seuil (1982): pp. 25,42 . 
este fenômeno de integração entre os gestos e movimentos corporais e o sentido proposicional, expresso verbalmente ${ }^{17}$.

Neste nível de sua manifestação, podemos dizer que a gestualidade incorpora-se à compreensão, dado o fato de que a individuação de suas funções é relativa a um sistema de convenções: o gesto da personagem não se confunde com um ato de indicar o que quer que seja, mas com o do protocolo retórico daquele que pede a palavra, ou mesmo a pronuncia. Neste último caso, o gestual adotado tem um sentido de reforço ou de ênfase ao registro propriamente verbal do discurso retórico. Um modo possível de enquadrar este aspecto da significação gestual é o de reconhecer, especialmente em seu emprego na representação visual, sua dimensão de ato ritualizado: na perspectiva de certos historiadores da arte, é o caráter ritualístico de certos gestos que oferece à pintura os materiais pelos quais a apresentação dinâmica dos motivos, na percepção, será selecionada para a representação pictórica ${ }^{18}$.

É precisamente este aspecto convencionalizado das atitudes corporais que leva Gombrich a tematizar o problema da representação dos gestos, como que cindido entre a expressividade (inerente aos sintomas) e a ritualidade (própria, por seu turno, aos símbolos): é assim evidente que a gramaticalidade das expressões gestuais oferece uma espécie de estrutura de base, sobre a qual podemos compreender o modo como o artista apreende a comunicação entre os elementos vivos de uma composição (sejam estes humanos ou não) ${ }^{19}$.

Mas a questão da representação dos gestos não pode estar restrita ao domínio da convencionalidade da compreensão das atitudes corporais: melhor dizendo, não é apenas por restituir-se à ordem ritualizada dos gestos

${ }^{17}$ Cf. da Vinci, Leonardo. Tratado de la Pintura (trad. cast. Diego Rejon de Silva). Madrid: Imprenta Real (1784): p. 21.

${ }^{18}$ Gombrich, Ernest. "Ritualized gesture and expression in art", op.cit.: p. 70.

19 O texto de Gombrich sobre os gestos rituais resulta de uma palestra conferida no contexto de um simpósio dedicado ao problema da ritualização do comportamento em animais e homens, na Royal Society, em junho de 1966. 
que o compreendemos, na economia própria do discurso visual; concorrem também para sua visão outros aspectos da expressão gestual, como aqueles que dizem respeito à tradução de estados interiores, de emoções e de disposições à ação.

Seu efeito, no plano da apreciação estética, não é da ordem de uma correspondência com um gesto já codificado no plano de um rito específico (os atos de indicar, orar, cumprimentar, pedir a palavra), mas como tradução de um estado de espírito, por sua vez encarnado em operadores que não são correspondentes a nenhuma destas ações específicas. Na fotografia que analisamos, esta ordem de questões sobre o sentido gestual se deixa verificar pela função que atribuímos às mãos que agarram o personagem principal, à sua direita e à sua esquerda (figs. 9 e 10):
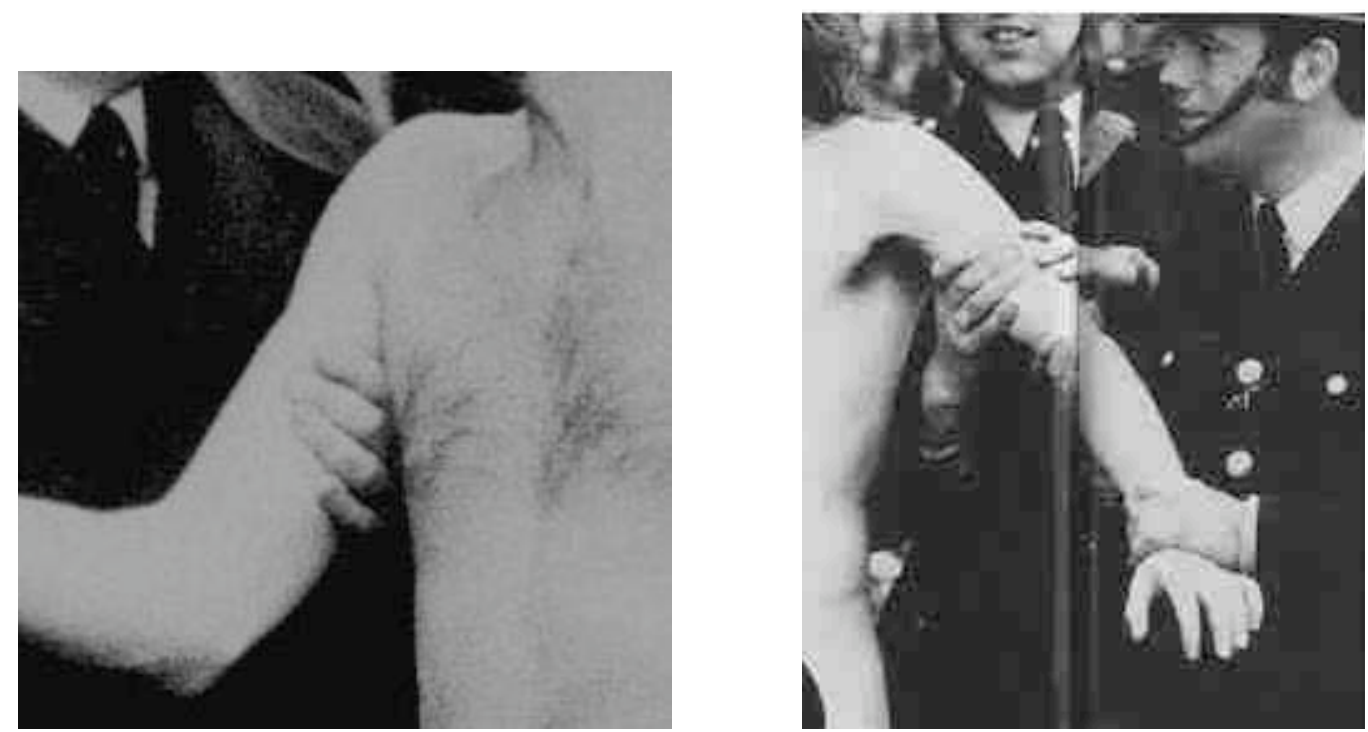

9. e 10. "Twickenham Streaker" (detalhe)

Nestes gestos, não encontramos qualquer correspondência ritualística para servir de base à leitura de suas funções no contexto da composição visual: seu sentido mais evidente diz respeito à expressão, iconicamente modelada, 
de uma certa força física com a qual os soldados detêm a personagem principal. Do ponto de vista da representação, estes gestos possuem um significado que é mais expressional e sintomático do que simbólico (não compreendemos seu sentido por restitú-lo a uma chave interpretativa determinada nas funções ritualísticas do gesto, mas, por participarmos simpaticamente do sofrimento desta personagem).

Começamos a nos restituir lentamente, aqui, ao centro da questão que nos está motivando a tematizar a fotografia na perspectiva do testemunho: trata-se da interrogação sobre o caráter vicário da experiência que esta imagem nos lega; pois, ainda que, no caso da fotografia, ela seja oriunda de um dispositivo que supostamente autentica a realidade (antes de representála), no caso do efeito que estes gestos assim fotografados nos suscitam, a estrutura da experiência que lega a estes seu devido valor expressivo é rigorosamente a mesma na qual poderíamos suprir a sensação do padecimento que é própria á experiência afetiva da pintura.

Muito embora, no caso da foto, esta função expressional do gesto não encontre repercussão aparente (por exemplo, numa fisionomia que denote a dor ou o incômodo da personagem em relação a seus antagonistas), ainda assim podemos restituir sua função, na economia da composição, como similar àquela que é típica da iconografia da paixão do Cristo (em Ticiano, por exemplo), e pela qual notamos o sofrimento de Jesus por correlacionarmos suas expressões de dor com a forte ação de seus algozes, expressa visualmente com bastante ênfase (fig. 11): neste ponto, nos damos conta de que a representação dos gestos, longe de apenas nos restituir ao significado mais fortemente normatizado nos ritos, também serve à produção de um efeito de experiência vicária de testemunho, de simpatia sensorial, igualmente através da figuração das ações humanas. 


\section{compós}

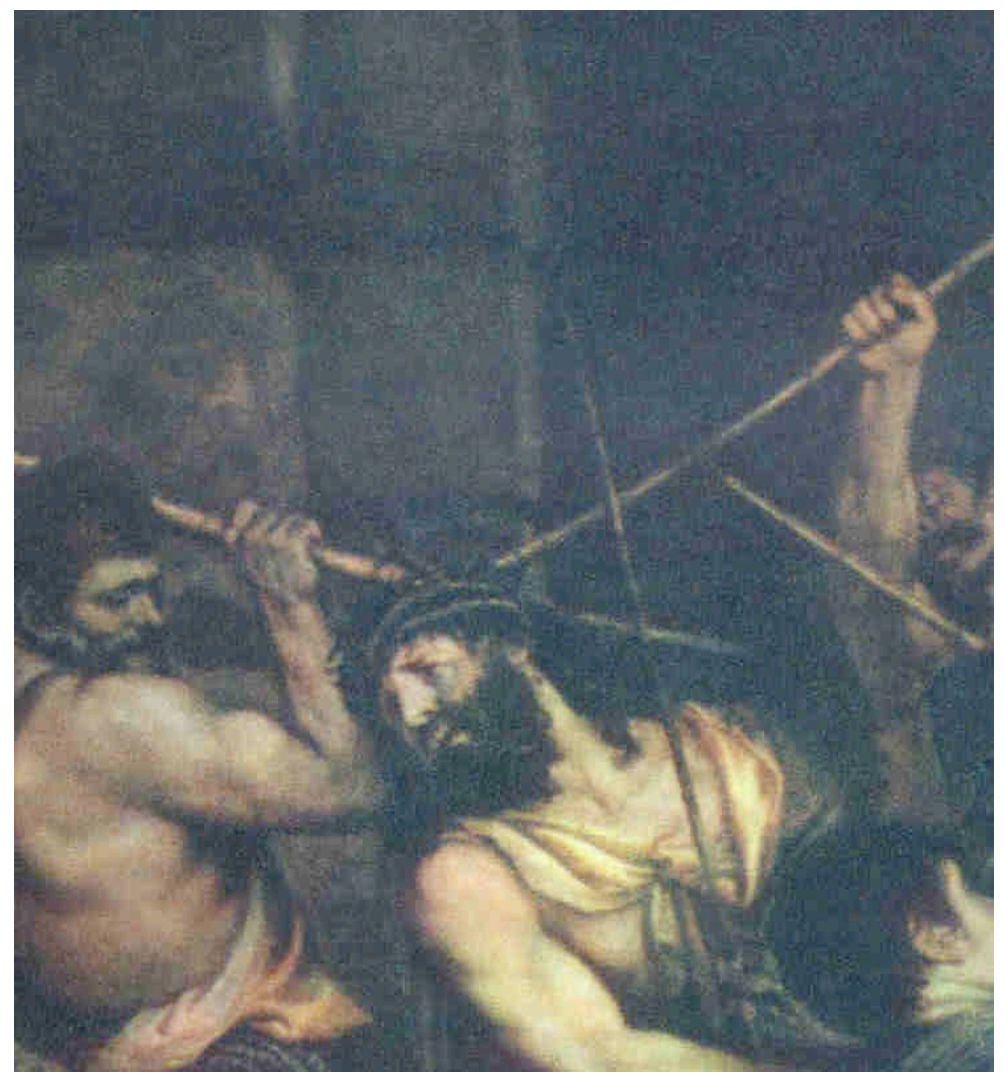

11. Ticiano, "Cristo coroado

de espinhos" c. 1542

(detalhe) - Museu do

Louvre

Ainda neste sentido do valor expressional associado ao gesto, um aspecto muito especial da representação pictórica da atitude corporal (que se repercute nos modos próprios à fotografia) é o da conceitualização do tempo dos acontecimentos, no plano da expressão gestual: sua representação, no contexto da pintura narrativa, atribui a este objeto um valor simbólico que unifica as dimensões temporais numa única forma visual (o fato de ser um instante aparente dissolve-se quando o gesto representado opera esta integração do tempo passado com o desdobramento do gesto no futuro).

Este fenômeno da integração temporal na imagem motivou fortemente o discurso de certas teorias da arte, especialmente concernidas com a elusividade das propriedades temporais da pintura: ao discutirem, por exemplo, as qualidades dramáticas ou narrativas de uma imagem, não se 
deixaram confundir pela impossibilidade dos ícones de renderem a sucessão temporal das ações, como se esta implicasse a igual impossibilidade de render a sensação do movimento no modo de se organizar pictoricamente seus motivos.

Quando não menos, os objetos da representação pictórica jamais se exibem a um espectador na pura simultaneidade de sua apresentação: ver os elementos de uma composição requisita primeiramente da visão do espectador que uma qualidade temporal esteja inscrita à ordem mesma de sua apreciação (significa que vemos um quadro por camadas, por porções do espaço visual rendido, estabelecendo relações entre seus diversos níveis, na sucessividade, jamais na instantaneidade de sua evocação). Por outro lado, a apresentação mesma dos elementos visuais, num sentido de representação, deve estar disposta de uma maneira tal a suscitar no quadro da experiência este aspecto de mudança, que é inerente a qualquer estado de coisas.

Assim sendo, até mesmo um motivo estático, como um retrato de fisionomia, pode revelar aspectos de alteração, ainda que sua apresentação se dê na simultaneidade do espaço. O que temos que considerar, na análise das propriedades figurativas do espaço, é o jogo configurativo das forças internas à composição na construção do efeito da impressão de movimento e de mudança: descrever, nestes termos, a gênese do sentido composicional pode trazer-nos riquíssimas sugestões de como operar a análise dos materiais icônicos da fotografia, sem que tenhamos de deixar de nos render à matéria visual mesma de sua apresentação ${ }^{20}$.

Segundo Gombrich, uma vez oferecido este patamar estrutural da compreensão do movimento gestual enquanto operadores do sentido temporal nas artes visuais, as diferenças históricas que se verificam nas várias

\footnotetext{
${ }^{20}$ Arnheim, Rudolf. "Movement". In: Art and Visual Perception: a psychology of the creative eye. Berkeley: University of California Press (1954): p. 378.
} 
tradições artísticas que se dedicaram a enfatizar a representação da ação humana parecem ter uma importância agora apenas relativa, uma vez defrontadas com o princípio estrutural que se exprime através desta operação pictórica (a saber, o de render o movimento gestual num único instante, firmado pictoricamente): o gesto humano, figurado na pintura e capturado na fotografia, unifica a diversidade e a sucessividade no plano da representação de um momento apenas teoricamente único; não podemos supor que o instante fotográfico seja rigorosamente perceptível enquanto tal, mas apenas uma especificação icônica do fluxo temporal das ações. Ainda assim, este instante especificado iconicamente, no fluxo temporal das ações, não se furta a, ao contrário, apenas reforça os vínculos com aquilo que parece próprio apenas às artes da sucessão, isto é, exprimir-se também no tempo ${ }^{21}$.

Ampliamos, neste ponto, a questão da significação gestual na representação pictórica, antes tomada como um operador puramente simbolizado nas funções próprias ao rito (como, por exemplo, para fixar o caráter distinto de uma personagem): este gestual nos interessa, na análise das operações discursivas próprias à construção do mundo visual na fotografia, enquanto coligada às funções icônicas de modelação e de conceituação do tempo numa matéria visual fixa; e aqui, a representação do tempo na imagem visual evoca as recomendações que a tradição estética do final do século XVIII fazia ao pintor de narrativas visuais, de que este procurasse ater-se ao princípio aristotélico do "ponto climático" das ações, de modo a fixar neste o objeto de seu interesse para a representação ${ }^{22}$.

\footnotetext{
${ }^{21}$ Gombrich, E.H. "Moment and movement in art". In: The Image and the Eye, op.cit.: pp. 53,55 .

${ }_{22}$ Dentre as várias referências da estética romântica que trataram a questão da representação do tempo na pintura, podemos destacar o Laoconte, de Lessing, identificando nele as distinções entre as artes do espaço (como a pintura) e as do tempo (como a música e a poesia), assim como as impossibilidades de restituição mútua dos procedimentos de cada uma delas (o que restringiria, neste caso, a pintura à representação das ações restrita a um único instante, $o$ qual deve ter precisamente as características do instante climático de uma ação, não obstante esta ter se dado efetivamente num fluxo mais extenso de tempo). Comentando esta herança
} 
Quando Gombrich avalia as conseqüências da introdução dos efeitos de instantaneidade, próprios à representação fotográfica das ações (nos experimentos clássicos de Muybridge com o movimento de galope de cavalos), nota também a impressão de estranhamento que as primeiras testemunhas deste experimento visual confessavam em relação à suposta objetividade dos registros fotográficos do movimento animal: os critérios de correção da representação mais familiares àquele período eram os da pintura de ações, e nestas os animais eram representados num vôo virtual, com as quatro patas totalmente fora do chão; a resultante desta experiência, para o historiador, é a de que estes critérios não possuem um fundamento objetivo, ainda que sua vigência seja explicada nestes termos.

Isto quer dizer que o caráter testemunhal que atribuímos a certas imagens não pode ser explicado de modo causal (isto é, não decorrem de uma percepção imediata destes caracteres), mas pelo concurso de hábitos perceptivos, sedimentados cultural e historicamente: de fato, nos parece distante a idéia deste estranhamento de nossos antepassados em relação à fotografia instantânea, já que este mesmo efeito da captura do movimento nos instantâneos nos é claramente familiar (ele é um elemento da legibilidade contemporânea da imagem, do mesmo modo que o galope voador dos cavalos, na pintura, o era para os espectadores do século XIX, sendo relativamente independente de qualquer apelo à objetividade das sensações visuais).

No caso dos gestos e da atitude corporal, o objeto da representação visual (quando concernida com a ação dos corpos), não é absolutamente a sucessão temporal (ao menos naquilo que possamos encontrar encarnado nas formas da representação), mas precisamente o instante: Gombrich

intelectual, Gombrich nota que nem mesmo a invenção da fotografia pareceu afetar o estatuto das distinções praticadas pela estética romântica naquele preciso momento, sobretudo quando levamos em conta que as primeiras fotografias requisitavam um enorme tempo de exposição para a fixação das imagens. Cf. Gombrich, E.H. "Moment and movement in art", op.cit.: pp. 42,43 . 
exemplifica luminosamente a questão a partir do caso da arte do still cinematográfico, que, por regra, não pode ser extraído dos fotogramas (isto é, não deriva analiticamente de uma segmentação das ações concretamente filmadas), mas que implica um outro modo de disposição dos elementos para a visão (algo mais próximo dos protocolos da pintura), e que valoriza precisamente o momento, em detrimento de seu desdobramento temporal ${ }^{23}$.

Isto posto, entretanto, devemos reconhecer que o foco de nossa discussão se deslocou da atenção sobre o caráter e as funções da expressão gestual na veiculação do sentido narrativo, próprio ás imagens pictóricas, para uma outra questão: os gestos capturados na fotografia ainda podem nos restituir a uma certa idéia de sucessão temporal que eles são capazes de conceitualizar (no nível de sua iconização); mas devemos nos interrogar sobre qual é mesmo o estatuto ontológico deste instante arrestado fotograficamente, pois da postulação de sua hipotética realidade é que dependem enormemente aquelas teorias que apostaram no caráter de radical indexicalidade da experiência das imagens fotográficas.

Se tivermos em conta aquilo a que certos autores designam como sendo o "isto foi" da fotografia (tão adequado, portanto, à apropriação que dela fazem todos aqueles regimes discursivos que se sustentam sobre a hipotética realidade da sucessão temporal) 24 , nosso ponto de vista sobre o caráter testemunhal da experiência fotográfica implicará decerto a noção de instante, não como possuindo existência eventual, mas enquanto determinada nas modelações icônicas necessárias à representação pictórica das ações.

\footnotetext{
23 In ibid.: p. 45.

24 Cf. Barthes, Roland. La Chambre Claire: note sur la photographie. Paris: Seuil (1980).
} 